\title{
Influence of growing conditions at different latitudes of Europe on strawberry growth performance, yield and quality
}

\author{
E. Krüger ${ }^{\mathrm{a}, *}$, M. Josuttis ${ }^{\mathrm{a}, \mathrm{b}}$, R. Nestby ${ }^{\mathrm{c}}$, T.B. Toldam-Andersen ${ }^{\mathrm{d}}$, C. Carlen ${ }^{\mathrm{e}}$ and B. Mezzetti ${ }^{\mathrm{f}}$ \\ ${ }^{\mathrm{a}}$ Geisenheim Research Center, Department of Pomology, Geisenheim, Germany \\ ${ }^{\mathrm{b}}$ RheinMain University of Applied Sciences, Geisenheim, Germany \\ ${ }^{\mathrm{c}}$ Bioforsk, Grasland and Landscape Division, Kvithamar, Stjordal, Norway \\ ${ }^{\mathrm{d}}$ Department of Agriculture and Ecology, Copenhagen University, Copenhagen, Denmark \\ ${ }^{\mathrm{e}}$ Agroscope Changins-Wädenswil Research Station ACW, Changins-Wädenswil, Switzerland \\ ${ }^{\mathrm{f}}$ D3A Università Politecnica delle Marche, Ancona, Italy
}

Received 19 November 2011; accepted 14 March 2012

\begin{abstract}
The site effect of five locations from north (Stjørdal, Norway, $63^{\circ} 36^{\prime} \mathrm{N}$ ) to south (Ancona, Italy, $43^{\circ} 31^{\prime} \mathrm{N}$ ) was evaluated in strawberry regarding yield performance, fruit quality, length of fruit developing time from anthesis to harvest start and length of the harvest season. Cv. Elsanta was grown at all sites while cv. Korona was cultivated in north and central Europe and cv. Clery in central and south Europe. Yield was more affected by seasonal and growing conditions than by latitude. Anthesis was delayed as influenced by cultivar up to 58 days from south to north and was nearly maintained until harvest start. Duration of fruit development was negatively related to daily mean temperature and increased with higher latitude. 29-34 days were required from anthesis to harvest start for cv. Elsanta, 29-36 for cv. Korona and 27-38 for cv. Clery. Corresponding GDD values (growing degree days; $3^{\circ} \mathrm{C}$ base temperature) were independent from latitude and accounted to 334-355 for cv. Elsanta, 301-385 for cv. Korona and 320-434 for cv. Clery. Daily mean temperature decreased about $2^{\circ} \mathrm{C}$ from south to north during anthesis to harvest start which induced a calculated 5.2 days longer fruit development period in the north. From harvest start to harvest end, GDD values varied for all cultivars between 297-402 GDD showing no influence of the latitude. However, simple summing of GDD values do not correctly describe the time of fruit development (from anthesis to the ripe fruit) for the whole fruiting period of a plant. GDDs for individually tagged flowers increased notably from the first third to the last third of the developing period due to increasing temperature as the season proceeded. The fruit quality standards dry matter, soluble solids and titratable acidity were influenced by latitude giving northern sites in general the highest values. Fruits grown at the southern sites were redder compared to those of the north.
\end{abstract}

Keywords: Fragaria ananassa Duch., latitude, pre-harvest temperature, PAR, fruit development, internal fruit quality, fruit colour

\section{Introduction}

Within the wide range of factors influencing plant performance and yield potential of strawberry (Fragaria $x$ ananassa Duch.), temperature and day-length, both influenced by latitude, are the most important. Especially

*Corresponding author: E. Krüger, Geisenheim Research Center, Department of Pomology, von Lade-Straße 1, 65366 Geisenheim, Germany. Tel.: +49 6722 502563; Fax: +496722 502560; E-mail: Krueger@fa-gm.de. 
temperature impairs various physiological processes in the strawberry plant like chilling requirement, onset of flowering and time of ripening. Unfavourable temperature conditions are responsible for freezing injuries on plants during winter or flower frost in spring. In addition to photoperiod, a strong interaction of temperature and day-length determine the transition from vegetative to floral meristem in June-bearing or Single-bearing cultivars [10] with considerable variation in cultivar response to temperature and photoperiod for flower induction [30].

Newly bred cultivars are tested worldwide annually to identify genotypes well adapted to regional conditions and breeders are interested in performance and stability of their cultivars over a range of environmental conditions. However, although Pritts and Luby [27] gave an excellent overview about useful stability indices for strawberry cultivar trials, knowledge about genotype adaptation and genotypexenvironment interactions are limited and only few evaluations have been made out in the near past in Europe on modern cultivars [8, 12, 19]. A better understanding how environmental constraints influence plant performance is important for breeding new genotypes adapted to north and south, but also for their adaption to the prospective global climatic changes.

Beside aroma, content of sugar and acid mainly affect strawberry fruit taste [1], which is together with fruit colour and firmness an important attribute for consumer acceptance. As was shown in a recent study [13], differences in temperature and light intensity as an effect of varying cultivation techniques can affect these fruit quality traits. However, very little is known on the impact of latitude on fruit colour, soluble solids or acidity in strawberry fruit.

Accordingly, this study aimed to characterise the pre-harvest climatic growing conditions of five sites throughout Europe from Mid Norway to Northern Italy, covering a distance of more than $2000 \mathrm{~km}$, and to evaluate the response of three Single-bearing cultivars to these varying latitudes and growing conditions.

\section{Materials and methods}

\subsection{Experimental sites, plant material and cultivation}

The trial was carried out under open-field conditions from 2006-2009 for three cultivation cycles at five cultivation conditions: Stjørdal, Norway (Stj-N), Copenhagen, Denmark (Cop-DK), Geisenheim, Germany (Gei-D), Conthey, Switzerland (Con-CH) and Ancona, Italy (Anc-I). Details of the respective latitude, altitude, annual mean temperature and precipitation, soil type and soil $\mathrm{pH}$ are given in Table 1.

Three cultivars were chosen for the study: the Dutch cultivars Elsanta and Korona which have been cultivated for more than two decades in the fresh market in Central and North Europe, respectively, and the Italian cultivar Clery which has become common for early production during the last 10 years in Central South Europe and Italy. Cv.

Table 1

Geographical, climatic and soil conditions at five sites in Europe and temperature conditions during the strawberry seasons 2007-2009 at these sites

\begin{tabular}{|c|c|c|c|c|c|}
\hline & Stj-N & Cop-DK & Gei-D & Con-CH & Anc-I \\
\hline Latitude & $63^{\circ} 36^{\prime} \mathrm{N}$ & $55^{\circ} 40^{\prime} \mathrm{N}$ & $49^{\circ} 59^{\prime} \mathrm{N}$ & $46^{\circ} 12^{\prime} \mathrm{N}$ & $43^{\circ} 31^{\prime} \mathrm{N}$ \\
\hline Altitude & $38 \mathrm{~m}$ & $25 \mathrm{~m}$ & $95 \mathrm{~m}$ & $480 \mathrm{~m}$ & $46 \mathrm{~m}$ \\
\hline Annual mean temperature* $\left({ }^{\circ} \mathrm{C}\right)$ & 5.6 & 8.2 & 10.5 & 9.6 & 13.6 \\
\hline Annual mean precipitation* (mm) & 733 & 523 & 543 & 506 & 823 \\
\hline Soil type & Silty loam & Sandy loam & Sandy loam & Sandy loam & Sandy loam \\
\hline Soil pH & 6.2 & $6.5-7.0$ & $6.5-7.0$ & 7.7 & 7.9 \\
\hline \multicolumn{6}{|c|}{ Temperature during the strawberry seasons $2007-2009$} \\
\hline Mean & $14.6(0.7)$ & $14.9(0.2)$ & $16.5(0.8)$ & $15.9(0.3)$ & $16.6(0.7)^{* *}$ \\
\hline Minimum & $9.7(1.1)$ & $9.9(1.0)$ & $8.8(1.2)$ & $9.8(0.8)$ & $7.2(2.1)^{* *}$ \\
\hline Maximum & $19.0(0.7)$ & $19.5(1.1)$ & $24.3(1.2)$ & $21.8(0.2)$ & $26.8(0.8)^{* *}$ \\
\hline
\end{tabular}

Standard deviation in brackets; ${ }^{*} 1971-2000 ;{ }^{* *}$ years 2007 and 2009 only. 
Elsanta was cultivated at all sites, while cv. Korona was planted in Stj-N, Cop-DK and Gei-D. Cv. Clery was tested in Gei-D, Con-CH and Anc-I.

At each site, strawberry plants were cultivated as common for the region. This means, that at Stj-N and Cop-DK potted runner plants were set in Mid-August 2006 and maintained as perennials the following three years for plant data collection. At $\mathrm{Stj}-\mathrm{N}$ plants were covered by winter- fleece to protect them against winter-freezing injuries. In contrast to the perennial system of the northern sites, trial fields were only harvested for one season at Gei-D, Con-CH and Anc-I. This required a yearly replanting prior to the harvest year. Planting was conducted at Gei-D and Con-CH always in the first week of August using potted runner plants, except of cv. Clery in 2007 at Gei-D when planting was in the last week of August. Anc-I used cold stored plants set at the last week of July. The experimental layout at the different site consisted of three replications with 15-40 plants per plot except for Anc-I in 2009, where cv. Clery was planted in one plot only. Plant protection, fertilization and irrigation were performed according to local guidelines.

\subsection{Plant and climatic data collection}

At all sites, for each cultivar onset of flowering (50\% of the plants with one flower), beginning and end of harvest period were recorded and fruit developing time including ripening was calculated as calendar days from anthesis to harvest start. At harvest, fully ripe fruits were picked two to three times a week. Yield including misshapen and rotten fruit was determined for each cultivar per replicate at each site and in each year and expressed as g/plant. At each harvest date, 20 fruits were weighted to calculate the mean fruit weight $(\mathrm{g})$ of the whole harvest period.

At each site, the environmental conditions were recorded at site or in a nearby meteorological station less than $15 \mathrm{~km}$ away. Air temperature was measured hourly in $2 \mathrm{~m}$ height to calculate growing degree days (GDD) based on $3^{\circ} \mathrm{C}$ as used by Døving and Måge [6]. GDDs were calculated according to the following equation GDD $=\left[\left(\mathrm{T}_{\max }+\mathrm{T}_{\min }\right) / 2\right]-$ $\mathrm{T}_{\text {Base }}[25]$ and were accumulated within the following phenological phases: a) from anthesis until harvest start and b) between start and end of harvest.

To characterise the impact of latitude on fruit development over the entire blooming period, all flowers of 5-10 plants per cultivar were individually tagged at anthesis (white petals are visible) in a two to three days interval at four sites in 2008 and 2009. Fruit developing and ripening time was also calculated from anthesis until harvest and expressed as calendar days and the corresponding GDD values.

To compare the effect of latitude with increasing day-length from south to north the photosynthetically active radiation (PAR, expressed as mol photons $\mathrm{m}^{-2} \mathrm{~d}^{-1}$ ) was measured. Daily mean PAR was calculated for three phenological periods a) from anthesis to harvest start, b) between harvest start and harvest end and c) from anthesis to harvest date of the individually tagged flowers/fruits. At Stj-N, PAR was calculated from the global radiation: PAR $\left(\mathrm{mol} \mathrm{m}^{-2} \mathrm{~d}^{-1}\right)=$ Global radiation $\left(\right.$ Watt $\left.\mathrm{m}^{-2}\right) \times 4.6 \times 0.46\left(4.6\right.$ is the factor for transforming Watt $\mathrm{m}^{-2}$ into $\mathrm{mol} \mathrm{m}{ }^{-2}$ [28], factor 0.46 refers to the fact that plants only use about $46 \%$ of global radiation for photosynthesis.

\subsection{Fruit quality characteristics: Dry matter, soluble solids, titratable acidity, fruit colour}

Fruit sampling and sample preparation are described in detail by Josuttis et al. [16]. Briefly, at all sites, samples of $500 \mathrm{~g}$ of healthy fruit per replicate were collected twice in the middle of the harvest period. Fruit were sliced, shock frozen in liquid nitrogen, milled to powder and sent to the Geisenheim Research Center for analyses. After thawing the strawberry powder, the soluble solid content (SSC) was directly measured in the resulting puree with a digital refractometer (A. Krüss Optotronic GmbH, Hamburg, Germany); the dry matter content (DM) was determined by mixing $5 \mathrm{~g}$ of powder with sea sand and drying for $4 \mathrm{~h}$ hours at $103^{\circ} \mathrm{C}$; titratable acidity (TA) was determined by homogenisation of 5 grams of powder in $50 \mathrm{~mL}$ distilled water and adjusting the $\mathrm{pH}$ value to 8.1 with $0.33 \mathrm{~mol} \mathrm{\textrm {L } ^ { - 1 }}$ sodium hydroxide solution.

In one to three years, colour was recorded up to two times per harvest season of 6-20 fruits per replicate at all sites except Stj-N, with a spectrometer using the CIE L*a*b* colour space by measuring the fruit surface on the site exposed and opposite to the sun. The $L^{*}$ value represents colour lightness $(0=$ black and $100=$ white $)$ while the $a^{*}$ coordinates ranged from red $\left(+a^{*}\right)$ to green colour $\left(-a^{*}\right)$ and the $b^{*}$ scales stands for a change from yellow $\left(+b^{*}\right)$ to blue $\left(-b^{*}\right)$. As recommended by Hung [15] for colour measurements in food, colour saturation was calculated as chroma $\mathrm{C}^{*}=\sqrt{ }\left(\mathrm{a}^{* 2}+\mathrm{b}^{* 2}\right)$ and hue angle as $h=\arctan \left(\mathrm{b}^{*} / \mathrm{a}^{*}\right)$ with $0^{\circ}=$ red-purple, $90^{\circ}=$ yellow, $180^{\circ}=$ bluish-green 
Table 2

Fruit yield and fruit weight of three strawberry cultivars at five sites in Europe

\begin{tabular}{lccc}
\hline Site & Elsanta & Korona & Clery \\
\hline Yield (g per plant) & & & \\
Stj-N & $111.7(58.1)$ & $139.7(63.8)$ & \\
Cop-DK & $469.7(176.3)$ & $797.2(278.0)$ & \\
Gei-D & $629.5(322.9)$ & $482.9(170.0)$ & $581.0(392.5)$ \\
Con-CH & $443.6(256.2)$ & & $536.9(58.9)$ \\
Anc-I & 261 & & $621.3(155.3)$ \\
Fruit weight $(g)$ & & & \\
Stj-N & $13.3(3.6)$ & $15.8(4.6)$ & \\
Cop-DK & $15.5(0.7)$ & $16.3(1.5)$ & \\
Gei-D & $16.2(1.8)$ & $16.0(1.1)$ & $18.6(0.2)$ \\
Con-CH & $16.1(2.0)$ & & $15.1(0.9)$ \\
Anc-I & 14.5 & & $15.0(3.1)$ \\
\hline
\end{tabular}

Standard deviation in brackets. Data are means of the years 2007-2009 except for cv. Elsanta at Stj-N (2008-2009) and Anc-I (2007), cv. Clery at Gei-D (2008-2009) and Anc-I (2007, 2009).

and $270^{\circ}=$ blue. Strawberry fruits with high chroma values are intense in colour while those with low values have a low-saturated colour and appear pale. An increase of the hue value represents a change of the fruit colour from red to orange.

\subsection{Statistics}

All statistics were performed using SPSS for Windows, version 17.0. No analysis of variance was calculated for yield and fruit weight because other effects than latitude affected these parameters. Instead, after calculating means per year, mean values over the years and standard deviations (SD) among years were determined. The variances for DM, SSC and TA were inhomogeneous mainly because of strong variation between sampling dates. Therefore, to verify statistical differences $(P \leq 0.05)$ for these data, means were compared with Tamhane's test. For this test, homogeneity of variances is not required. Since fruit colour parameter $\mathrm{L}^{*}$, chroma and hue angle were assessed with a different number of evaluations per site and year, also no analyses of variance were performed. Instead, these data were given as box-plots. To explore the relationship between the length of the different phenological plant stages and fruit quality characteristics with daily temperature parameters and daily mean PAR during the preceding weeks, linear correlations after Pearson were performed. Only significant correlation coefficients are presented, while insignificant coefficients are omitted for clarity.

\section{Results and discussion}

\subsection{Yield and fruit weight}

There was variation in fruit yield for cvs. Elsanta and Korona between the sites giving the impression of low adaptability to some of these sites. In contrast, cv. Clery varied only marginally between sites (Table 2). However, the observed differences of the three cultivars between the growing sites were not basically linked to latitude and thus climatic differences, but to seasonal and growing effects. This is expressed by the partly high standard deviation among the years.

At Stj-N, yield per plant was generally low. For the cv. Korona a yield of 300-400 g per plant could be expected at that latitude. The lower result in this study was mainly caused by injury from the strawberry beetle (Stelidota 
geminata). Also, some plants were weakened by winter injury accumulating over the years, which often happens in northern climate [29] and generating a reduction in yield capacity [26]. Cv. Elsanta plants developed only few flowers. This might be caused by a poor adaption to northern climate with regard to optimal day and night temperatures for flower initiation in the autumn of the previous year, as stated by others [30, 32].

At Cop-DK, the yield variation among the years could be explained by the traditional perennial production of the northern sites, where fields were normally kept for more than two years [29]. This system generated plants with numerous crowns and increased yield potential in the second year while in the third year plant performance was reduced as expected when plants get older.

At Gei-D, the high SD values for the yield of cvs. Elsanta and Korona was induced by an unsaturated chilling requirement in the winter 2006/2007, which was not an effect of latitude per se but of exceptional warm conditions with less than 1000 hours of chilling $\left(0-7^{\circ} \mathrm{C}\right)$ during November until January. The plants showed reduced petiole and inflorescence length, both typical signs of plants receiving low chilling [24]. For instance, cv. Elsanta needs at least 1000-1300 hours below $7^{\circ} \mathrm{C}[2,23,31]$ for optimum development. The high SD for yield of cv. Clery was affected by the delayed planting to the end of August 2007 which caused fewer crowns and thereby a reduced number of flower stalks and flowers in 2008 [20].

At Con- $\mathrm{CH}$, a severe infection with Verticillium-wilt reduced the yield of cv. Elsanta in 2007.

The low yield potential of cv. Elsanta at Anc-I in 2007 was negatively affected by latitude, since accumulated chilling hours reached a common value for this site but was insufficient for this cultivar. Therefore, cv. Elsanta was not grown for more years at Anc-I.

However, in a Polish long-time evaluation, yield was significantly positively correlated with temperature shortly before and during anthesis [14], while a Norwegian long-time study concluded that climatic conditions during flower induction and flower differentiation were more important for yield than those during flowering and ripening [7]. Since temperature decreased with increasing latitude, further studies should focus on this subject again. Furthermore, when comparing northern to southern sites of Europe, a two year production system should be applied at all locations to level off the effects of different plant age on the production potential, so a putative impact of latitude on this economic important parameter will become clearer.

Fruit weight of each cultivar was slightly affected by seasonal variation within the different sites and their local climatic and cultivation conditions (Table 2), but no relationship between latitude and fruit weight was detectable.

\subsection{Temperature and PAR from anthesis until end of harvest}

Temperature values of the strawberry season for the years 2007-2009 are given in Table 1. The greatest amplitudes between day (maximum) and night (minimum) temperature were observed for Anc-I and Gei-D. The highest daily mean PAR values during the fruit development period were recorded for Stj-N and Con-CH (Tables 4 and 5). For $\mathrm{Stj}-\mathrm{N}$, this can be explained by the increased day-length due to the high latitude and also by a pronounced delay of the season (Table 3). Despite slight differences in latitude between Con-CH and Gei-D, PAR values at Con- $\mathrm{CH}$ were notably higher due to more sunny days.

\subsection{Temperature effects on anthesis and fruit development}

\subsubsection{Anthesis}

Anthesis was delayed from south to north reflecting the influence of latitude and thus decreasing temperature from south to north. Anthesis of cvs. Elsanta and Korona started 40-42 days later at Stj-N than at Gei-D or Con-CH and for cv. Elsanta even 58 days later when compared to Anc-I (Table 3). Although Con-CH is situated more south than Gei-D, suggesting an earlier flowering, no great differences were observed between both sites for cv. Elsanta and Clery. This is probably an effect of higher altitude at $\mathrm{Con}-\mathrm{CH}$ resulting in a later vegetation start. Anthesis of cv. Clery was 23-28 days later at Con-CH and Gei-D as compared to Anc-I. Although start of vegetation was not recorded in this study, anthesis is generally correlated with temperature of the previous weeks. Further studies should quantify, after start of vegetation, the influence of temperature on emergence of inflorescence and anthesis. Also, plant condition may affect time of anthesis. Data of a greenhouse experiment showed a 5 day earlier flowering of 
Table 3

Date of anthesis and harvest start of three strawberry cultivars at five sites in Europe

\begin{tabular}{|c|c|c|c|c|c|c|}
\hline \multirow[t]{3}{*}{ Site } & \multicolumn{6}{|c|}{ Days after 1 January } \\
\hline & \multicolumn{3}{|c|}{ Anthesis } & \multicolumn{3}{|c|}{ Harvest start } \\
\hline & Elsanta & Korona & Clery & Elsanta & Korona & Clery \\
\hline Stj-N & $152(5.7)$ & $156(0.6)$ & & $186(0.7)$ & $185(1.0)$ & \\
\hline Cop-DK & $131(2.3)$ & $130(2.1)$ & & $165(3.1)$ & $168(6.4)$ & \\
\hline Gei-D & $112(6.1)$ & $114(6.5)$ & $113(7.8)$ & $141(11.1)$ & $144(7.6)$ & $144(7.1)$ \\
\hline Con-CH & $110(7.6)$ & & $108(7.5)$ & $139(8.2)$ & & $135(6.1)$ \\
\hline Anc-I & 94 & & $85(2.1)$ & 124 & & $122(6.4)$ \\
\hline
\end{tabular}

Standard deviation in brackets. Data are means of the years 2007-2009 except for cv. Elsanta at Stj-N (2008-2009) and Anc-I (2007), cv. Clery at Gei-D (2008-2009) and Anc-I (2007, 2009).

Table 4

Calendar days, growing degree days (GDD, base temperature $3^{\circ} \mathrm{C}$ ), daily mean temperature and daily mean PAR between anthesis and harvest start for three strawberry cultivars at five sites in Europe

\begin{tabular}{lllcc}
\hline Site & Days & GDD $\left({ }^{\circ} \mathrm{C}\right)$ & $\begin{array}{c}\text { Mean temperature } \\
\left({ }^{\circ} \mathrm{C}\right)\end{array}$ & $\begin{array}{c}\text { Mean PAR }(\mathrm{mol} \\
\left.\text { photons } \mathrm{m}^{-2} \mathrm{~d}^{-1}\right)\end{array}$ \\
\hline $\begin{array}{l}\text { Elsanta } \\
\text { Stj-N }\end{array}$ & $34(6.4)$ & $334(63.2)$ & $13.3(0.1)$ & $43(1.7)$ \\
Cop-DK & $34(3.5)$ & $355(38.1)$ & $13.7(0.9)$ & $28(4.6)$ \\
Gei-D & $29(5.8)$ & $352(63.7)$ & $15.4(0.7)$ & $32(5.2)$ \\
Con-CH & $29(5.0)$ & $353(52.6)$ & $15.4(0.4)$ & $41(5.1)$ \\
Anc-I & 30 & 406 & 16.1 & - \\
Korona & & & & $44(1.3)$ \\
Stj-N & & $301(13.4)$ & $13.6(0.4)$ & $28(4.6)$ \\
Cop-DK & $29(1.5)$ & $381(45.0)$ & $13.8(0.9)$ & $31(2.8)$ \\
Gei-D & $36(5.5)$ & $385(23.6)$ & & \\
Clery & $31(2.1)$ & & $14.6(0.4)$ & $28(3.5)$ \\
Gei-D & & $364(0.7)$ & $14.8(1.1)$ & $41(6.6)$ \\
Con-CH & $32(0.7)$ & $320(33.8)$ & $14.1(0.8)$ & - \\
Anc-I & $27(4.4)$ & $434(74.1)$ & & \\
\hline
\end{tabular}

Standard deviation in brackets. Data are means of the years 2007-2009 except for cv. Elsanta at Stj-N (2008-2009) and Anc-I (2007), cv. Clery at Gei-D (2008-2009) and Anc-I (2007, 2009).

waiting bed plants compared to cold stored plants [22]. This resulted in different base temperatures for the rate of progress to flowering and thus for calculating GDDs from start of growing until anthesis.

\subsubsection{Period between anthesis and harvest start}

As an average of all sites, years and cultivars, about 27-38 days were needed from anthesis to harvest start (Table 4). In general, duration of fruit development was negatively related to daily mean temperature and thus increased with higher latitudes. For instance, cv. Elsanta required 5 days more to ripen at Stj-N and Cop-DK compared to Gei-D and Con-CH showing a significant dependence on daily mean temperature $\left(r=-0.644^{*}, p \leq 0.05\right)$. Even with a limited data set, the calculation of a linear regression for cv. Elsanta with daily mean temperature as the variable resulted in the following equation: $y=-2.694 \times+70.460\left(r^{2}=0.3410, p=0.025\right.$, standard error of estimate $\left.=3.870\right)$. This means 
Table 5

Calendar days, growing degree days (base temperature $3^{\circ} \mathrm{C}$ ), daily mean temperature and daily mean PAR between harvest start to harvest end for three strawberry cultivars at five sites in Europe

\begin{tabular}{lllcr}
\hline Site & Days & GDD $\left({ }^{\circ} \mathrm{C}\right)$ & $\begin{array}{c}\text { Mean temperature } \\
\left({ }^{\circ} \mathrm{C}\right)\end{array}$ & $\begin{array}{c}\text { Mean PAR }(\mathrm{mol} \\
\left.\text { photons } \mathrm{m}^{-2} \mathrm{~d}^{-1}\right)\end{array}$ \\
\hline $\begin{array}{l}\text { Elsanta } \\
\text { Stj-N }\end{array}$ & $29(3.5)$ & $347(54.0)$ & $15.4(0.5)$ & $36(2.1)$ \\
Cop-DK & $22(3.1)$ & $300(29.5)$ & $16.6(1.2)$ & $27(0.5)$ \\
Gei-D & $27(3.6)$ & $402(36.3)$ & $17.7(0.5)$ & $31(1.2)$ \\
Con-CH & $24(2.6)$ & $326(24.4)$ & $16.5(0.6)$ & $42(4.7)$ \\
Anc-I & 15 & 245 & 16.1 & - \\
Korona & & & & $40(4.8)$ \\
Stj-N & $23(2.4)$ & $297(29.7)$ & $16.1(0.6)$ & $29(0.8)$ \\
Cop-DK & $23(7.0)$ & $305(61.6)$ & $17.0(1.9)$ & $32(1.5)$ \\
Gei-D & $24(3.5)$ & $362(35.1)$ & $18.0(0.8)$ & \\
Clery & & & & $33(1.2)$ \\
Gei-D & & & $19.0(1.6)$ & $42(3.2)$ \\
Con-CH & $22(6.0)$ & $344(52.2)$ & $16.8(0.6)$ & - \\
Anc-I & $28(1.6)$ & $379(9.7)$ & $20.7(1.3)$ & \\
\hline
\end{tabular}

Standard deviation in brackets. Data are means of the years 2007-2009 except for cv. Elsanta at Stj-N (2008-2009) and Anc-I (2007), cv. Clery at Gei-D (2008-2009) and Anc-I (2007, 2009).

that with a daily mean temperature of $15^{\circ} \mathrm{C}$ harvest start will be 30 days after anthesis, while at $16^{\circ} \mathrm{C}$ this will occur 2.6 days earlier. In our study, daily mean temperature decreased about $2^{\circ} \mathrm{C}$ (Table 4 ) from south (Con-CH) to north $(\mathrm{Stj}-\mathrm{N})$ for the period anthesis to harvest start, which would induce a calculated 5.2 days longer fruit developing time in the north. Døving and Måge [6] found in a study of a long time data series for Norway, mainly with cv. Senga Sengana, in a linear regression calculation that $1{ }^{\circ} \mathrm{C}$ higher temperature in June, approximately the month prior to harvest, caused a 4.1 days earlier start of the strawberry season. Le Mière et al. [22] identified for greenhouse experiments with constant temperature (between 14 and $28^{\circ} \mathrm{C}$ ) also a linear relationship with $1^{\circ} \mathrm{C}$ higher temperature accelerating first pick by 3 days of cv. Elsanta.

In contrast to the significant correlation coefficient between duration of fruit development and daily mean temperature for cv. Elsanta, no significant relationship was found for the cvs. Korona and Clery $(r=-0.429$ and -0.509 , respectively).

Expressing the duration of fruit developing in terms of GDD values, 334-355 GDD's (334-406 when including Anc-I) were recorded for cv. Elsanta, 301-385 for cv. Korona and 320-434 for cv. Clery (Table 4). This means that the GDD value for cv. Elsanta was relatively constant and independent from the growing sites and showing no influence of latitude. Although GDD values for cvs. Korona and Clery deviated a little bit more than for cv. Elsanta, also no clear north to south trend was detectable.

The lack of a close relationship between duration of fruit development and daily mean temperature for cvs. Korona and Clery and the exceeded deviation of calculated GDD values among the growing sites for these cultivars may have multiple explanations like seasonal plant and meteorological conditions. For instance, although daily mean temperature at Stj-N was comparable to Cop-DK, only 29 days were required from anthesis to harvest start for cv. Korona, and consequently, calculation of the corresponding GDD gave low values, also. Several internal factors influencing the yield potential (crown development, flower initiation in autumn and insufficient chilling) may have affected the fruit developing time also.

Moreover, at Anc-I, fruit development of cv. Clery was exceptionally long and corresponding GDD values high compared to the other two sites. Despite daily mean temperature differed only slightly between the three growing sites, minimum temperature at night was lowest at Anc-I (Table 1), which may have influenced fruit development rate at Anc-I negatively. 
Le Mière et al. [22] reported that waiting bed plants of cv. Elsanta required an accumulation of 891 GDD $\left(2.9^{\circ} \mathrm{C}\right.$ base temperature) from start of forcing in greenhouse until first pick while cold stored plants needed 831 GDD $\left(2.4^{\circ} \mathrm{C}\right.$ base temperature). Døving and Måge [6], using a base temperature of $3^{\circ} \mathrm{C}$, determined 782 GDD until start of harvest of cv. Senga Sengana when calculation started at 1 April, which is more or less the beginning of vegetation under Norwegian conditions. In both studies, higher GDD values were found as compared to our results. However, in our study, the first phenological stage evaluated was the emergence of first flower, while in the other two studies pre-anthesis temperature conditions were also included. Moreover, in the studies mentioned no information is given how GDD was calculated. As was shown by McMaster and Wilhelm [25], great differences in GDD values may occur when comparison to the base temperature is done after calculating the average temperature or the base temperature is compared with the maximum and minimum temperature individually before calculating the GDD value.

\subsubsection{Harvest season}

The observed delay in anthesis from south to north was almost maintained until harvest season. For example, at Stj-N harvest start for cvs. Elsanta and Korona were on average around 41-45 days later than at Gei-D (Table 3). Harvest start of cv. Clery at Gei-D was delayed by 7 days compared to Con-CH and by 22 days compared to Anc-I. In the mean of the three years, there was no north to south influence visible on the length of the harvest season (Table 5). However, length of harvest season was negatively related with daily mean temperature (cv. Elsanta $r=-0.399$; cv. Korona $r=-0.320$ ) but the correlation was significant for cv. Clery only $(r=-0.881, p \leq 0.01)$.

In this study different seasonal meteorological and growing conditions were observed influencing the length of the harvest season and thus overlapped a potential north to south influence. For example, a short season, also in combination with low daily mean temperatures, occurred when plants were rather small exhibiting only inflorescenses with low order flowers. This was the case at the northern sites in 2007, where low yield potential in the first year after planting is the reason for a perennial growing system. Also, an extremely short harvest season was noted for cv. Clery at Gei-D in 2008, where the delayed planting in 2007 also generated small plants with few crowns and low yield potential. In addition, an exceptional long harvest season occurred in 2007 at Gei-D for cvs. Elsanta and Korona ( 34 and 30 days respectively), even though the daily mean temperature of the harvest season was high with $17.4^{\circ} \mathrm{C}$ and $18.4^{\circ} \mathrm{C}$. Since saturated chilling requirement stops flower initiation $[9,33]$, it might be speculated that the long harvest season 2007 at Gei-D for both cultivars was a result of the insufficient chilling in the previous winter with additional flower initiation under inducing conditions in early spring, giving an asynchronous and long flowering period and thus a long harvest season.

Accumulated yield graphs presented the delayed season from south to north, but showed similar cropping pattern at all sites (Fig. 1A, cv. Elsanta as example). When the accumulated yield is linked to GDD values, the graphs nearly overlapped (Fig. 1B).

Over the different growing sites of this study, GDD values for the period harvest start until harvest end varied for cv. Elsanta from 300-402 (245-402 when including Anc-I), for cv. Korona from 297-362 and for cv. Clery from 344-397 (Table 5), showing no influence of the latitude. Greater variation in GDD values might be evoked by the above mentioned exceptions in length of harvest season due to seasonal meteorological and growing conditions.

\subsubsection{Fruit development period and GDD values of individually tagged flowers during the entire blooming time}

The required numbers of days from anthesis to harvest for individually tagged flowers increased from south to north (Table 6) but were more or less similar within a site when expressed in thirds of the whole harvest season. Again and as expected, fruit developing period was significantly negative correlated with daily mean temperature (Fig. 2). Consequently, all cultivars needed more days for fruit development in 2009 because of the lower daily mean temperature than in 2008. This seasonal trend overlapped the dependency from latitude. However, for cv. Elsanta data of the nordic sites Stj-N and Cop-DK could be separated in tendency from those of Gei-D and Con-CH, while for cv. Korona data of Gei-D only tended to distinguish from those of Cop-DK and Stj-N. For cv. Clery data of Gei-D and Con-CH overlapped.

When length of fruit development is expressed as GDD values (Table 6), a notable increase of GDDs was found from earlier to later fruit. In the average of all sites, cv. Elsanta required 382 and 451 GDDs for fruit development 
A) Harvest days
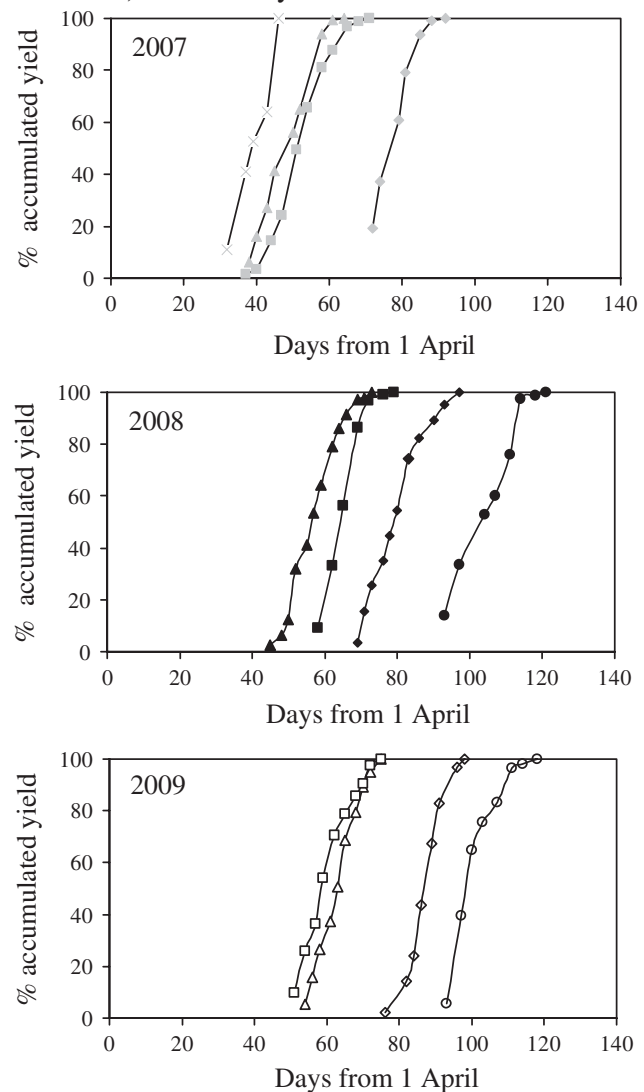

B) Growing degree days
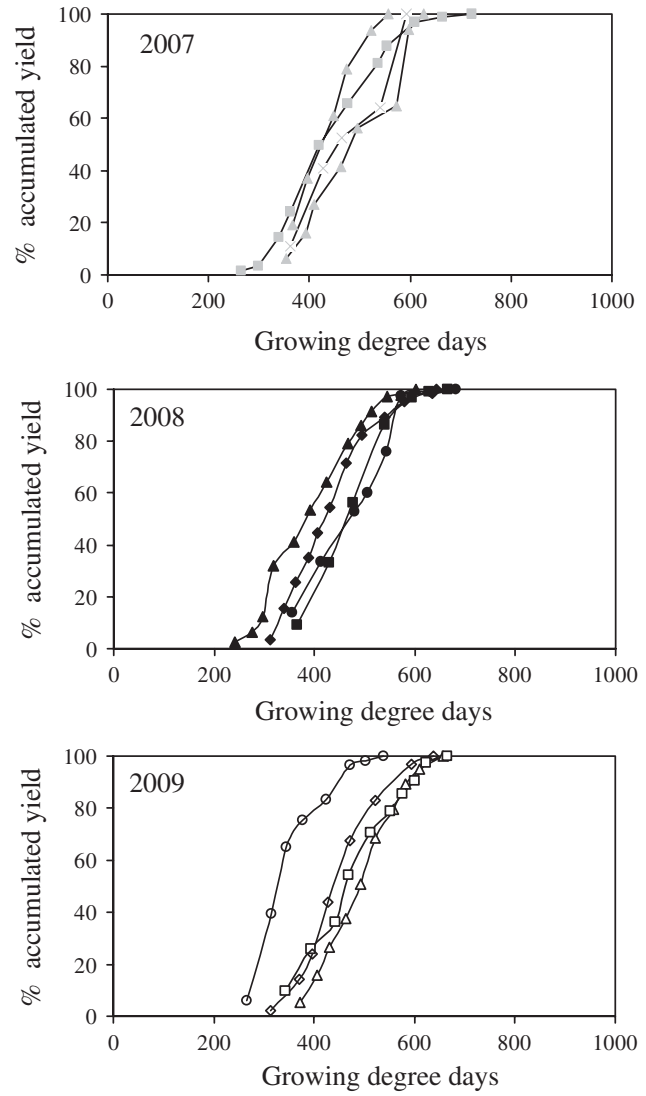

\begin{tabular}{|c|c|c|}
\hline - Stj-N 07 & Cop-DK $07 \square$ Gei-D 07 & $\triangle$ Con-CH $07 \times$ Anc-I 07 \\
\hline - Stj-N 08 & • Cop-DK 08 • Gei-D 08 & $\Delta$ Con-CH 08 \\
\hline - Stj-N 09 & $\diamond$ Cop-DK $09 \square$ Gei-D 09 & $\triangle$ Con-CH 09 \\
\hline
\end{tabular}

Fig. 1. Comparison of accumulated yield of cv. Elsanta, based on harvest days (A) or growing degree days, $3^{\circ} \mathrm{C}$ base temperature (B) in $2007-2009$.

during the first and last third of the harvest season, respectively, while for cv. Korona values of 370 and 482 and for cv. Clery values of 393 and 417 were determined.

Hence, these values for the first third of the harvest season were slightly higher than the GDD values calculated from anthesis to harvest start, only (Table 4). This might be explained by varying intervals (1-4 days) of tagging the flowers and also for different intervals for picking the fruits (2-4 days), both within and between sites. In a recent study, also higher GDD values were determined when fruits were picked at 3-4 days intervals as compared to daily harvest [18].

The notable increase of GDD values from the first to the last third of the harvest season was unexpected. However, since the individual flowers were tagged over the entire blooming period of 3-4 weeks, this includes the change from first order flowers to higher ranked ones, and it also means that fruit developing happens under increasing temperature as the season progressed. Thus, when length of the fruit developing period does not decrease during the harvest season as in our study, the accumulation of daily mean temperatures consequently will give increased GDD values. Also, in a Norwegian long-time study, late seasons, and hence seasons with high temperature conditions, were related to higher accumulated GDD values (base temperature 0,3 or $5^{\circ} \mathrm{C}$ ) than early seasons [6]. In contrast, Koch [18] reported similar GDD values (456-480) for strawberries of different fruit order and thus also over the entire fruiting season when using temperature measurements in $5 \mathrm{~cm}$ soil depth and a base temperature of $0^{\circ} \mathrm{C}$. Clearly, with such an approach, cooler temperatures were measured than at $2 \mathrm{~m}$ height, and in addition, temperature values 
Table 6

Calendar days and growing degree days (GDD base temperature $3^{\circ} \mathrm{C}$ ), between start of flowering to harvest for individually tagged flowers/fruits for three strawberry cultivars in two years at four sites in Europe (Data are expressed in thirds of the harvest season)

\begin{tabular}{|c|c|c|c|c|c|c|c|}
\hline \multirow[t]{2}{*}{ Site } & \multirow[t]{2}{*}{$\begin{array}{c}\text { No. of total harvest } \\
\text { days 2008/2009 }\end{array}$} & \multicolumn{3}{|c|}{$\begin{array}{l}\text { Days required from } \\
\text { anthesis until harvest }\end{array}$} & \multicolumn{3}{|c|}{$\begin{array}{c}\text { Growing degree days, } \\
\text { based on } 3^{\circ} \mathrm{C}\end{array}$} \\
\hline & & 1st third & 2nd third & 3rd third & 1st third & 2nd third & 3rd third \\
\hline \multicolumn{8}{|l|}{ Elsanta } \\
\hline Stj-N & $8 /$ & 34 & 35 & 34 & 361 & 365 & 419 \\
\hline Cop-DK & $9 / 8$ & 35 (3.7) & $35(3.0)$ & 37 (1.2) & $363(17.0)$ & $394(28.6)$ & $462(29.6)$ \\
\hline Gei-D & $6 / 8$ & $32(4.9)$ & $33(4.2)$ & $33(2.8)$ & $408(39.2)$ & $466(20.6)$ & $485(2.1)$ \\
\hline Con-CH & $9 / 4$ & $31(3.7)$ & $32(5.8)$ & 31 & $393(18.5)$ & $426(36.6)$ & 439 \\
\hline \multicolumn{8}{|l|}{ Korona } \\
\hline Stj-N & 9/ & 34 & 38 & 37 & 324 & 386 & 425 \\
\hline Cop-DK & $10 / 7$ & $36(4.5)$ & $38(3.3)$ & 41 (1.9) & $373(41.2)$ & $426(56.6)$ & $520(24.2)$ \\
\hline Gei-D & $8 / 8$ & $32(3.5)$ & $33(4.0)$ & $35(2.5)$ & $412(32.3)$ & $474(11.2)$ & $501(1.2)$ \\
\hline \multicolumn{8}{|l|}{ Clery } \\
\hline Gei-D & $7 / 8$ & $30(5.3)$ & $31(4.7)$ & $29(4.5)$ & $393(61.1)$ & $440(31.4)$ & 433 (13.6) \\
\hline Con-CH & $7 / 6$ & $32(4.1)$ & $32(6.7)$ & 29 & $393(0.3)$ & 425 (48.7) & 400 \\
\hline
\end{tabular}

Standard deviation in brackets. Data are means of the years 2008-2009 except for cvs. Elsanta and Korona at Stj-N (2008 only); at Con-CH no data were collected in the third part of the harvest season 2009.
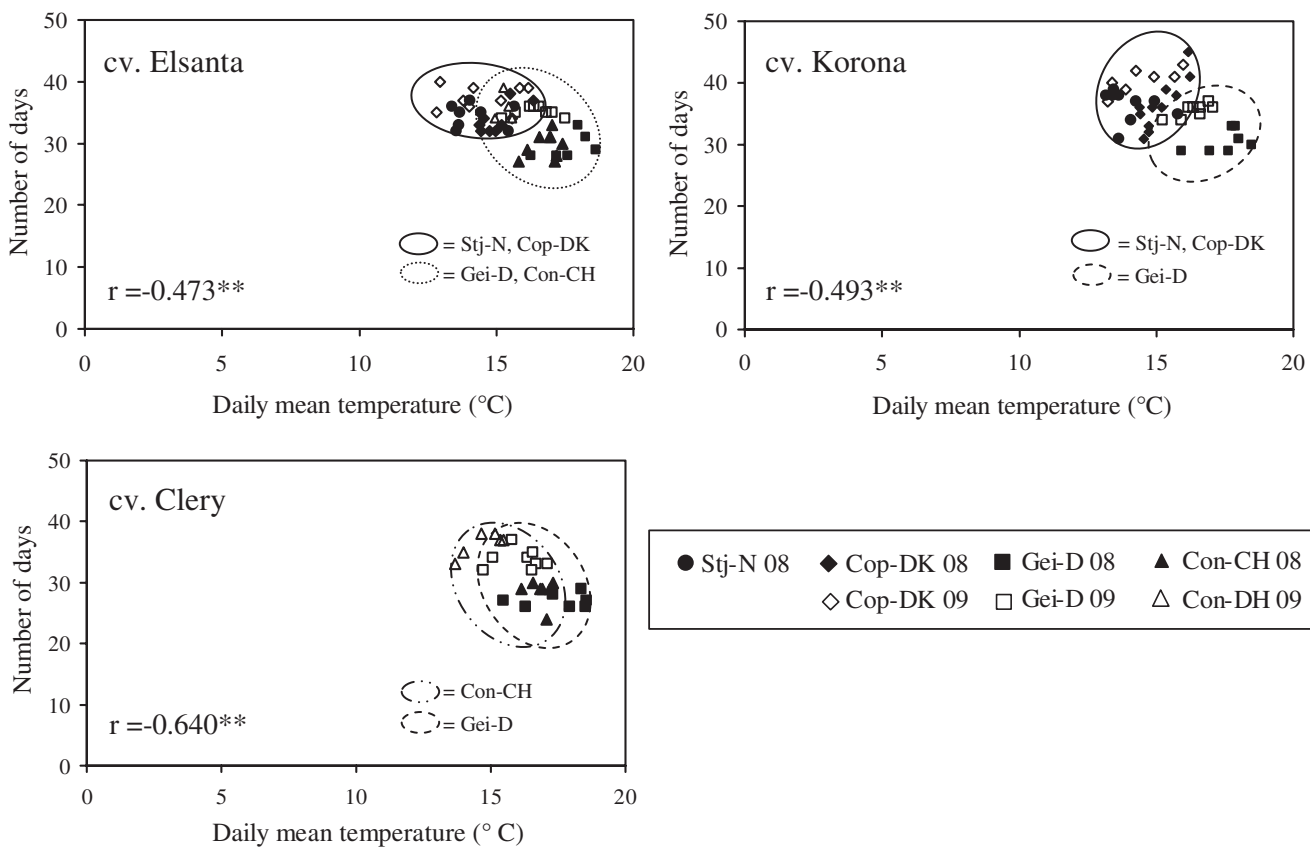

Correlation after Pearson, bivariat; ** $=\mathrm{p} \geq 0.01$

Fig. 2. Relationship between daily mean temperature and number of days required from anthesis until picking date of individually tagged flowers. 
showed less variation over the day and from day to day. Our own observation and the results of Døving and Måge [6] may indicate that aside temperature other environmental factors may affect rate of fruit development also.

Similarly, in a recent study with blackberry, the rate of fruit development was not predictable using heat unit models based on the sum of growing degree hours [3]. However, when integrating light integrals to the used model, the predictive value increased but was still not better than simply counting of calendar days. It might also be assumed, that beside a minimum also an optimum and a critical temperature exists for the rate of strawberry fruit development and that different temperatures should be weighted according to their effect on the rate of fruit development as it is done in a prediction model for blackcurrant [21]. Also, incorporation of an upper threshold in the GDD calculation may help to avoid overestimation of GDD values. Fruit developing rate was found to be linear in a temperature range from $12-28^{\circ} \mathrm{C}$ [22]. In the present study, maximum temperature above $30^{\circ} \mathrm{C}$ occurred several times during fruit development period at Anc-I and Gei-D, but not at the other sites. However, Carlen et al. [4] stated that net photosynthesis of strawberry plant was highest at $30^{\circ} \mathrm{C}$ and still reached $60 \%$ of the maximum level at $40^{\circ} \mathrm{C}$.

\subsection{The effect of PAR on the periods from anthesis to harvest start and from harvest start to harvest end}

PAR values during the periods from anthesis to harvest start, harvest start to harvest end and during the time of fruit developing of the individually tagged flowers were dominated by the high values at Stj-N and Con-CH (Tables 4 and 5). However, significant negative correlations were found for all cultivars with regard to number of days and daily mean PAR values from anthesis to harvest start and being significant for cvs. Korona and Clery $(r=-0.708$ and $r=-0.939$, respectively; $p \leq 0.05$ ). No significant relationship was found between harvest start and harvest end for any of the cultivars.

Our finding that increased PAR values reduced the period from anthesis to harvest start of cvs. Korona and Clery is conflicting with the results from Le Mière et al. [22]. They considered different planting dates and thus light and photoperiod condition and stated that first pick was only a function of temperature. However, in their experiments the differences in planting dates were just five weeks and thus radiation varied only marginally. It should also be mentioned that increased photosynthetic radiation is not an effect of latitude per se, but also of altitude as in the case of Con- $\mathrm{CH}$ and also of local meteorological conditions during fruit development. The last may perhaps be the reason why cv. Elsanta showed no significant relationship between time from anthesis to harvest start and PAR values, and for all cultivars also for the period from harvest start to harvest end.

\subsection{Inner fruit quality}

\subsubsection{Dry matter, soluble solids and acidity}

The fruit quality attributes DM, SSC and TA of cvs. Elsanta and Korona were all influenced by latitude and northern sites gave in general the highest values (Table 7). For cv. Elsanta, there were negative correlations for all measured fruit quality attributes and daily mean and maximum temperature during the preceding week, while for cv. Korona only DM and SSC were statistically negatively linked with these temperature parameters (Table 8). The one-week-based-relationships were stronger than those of the previous two or three weeks.

Decreased values of fruit DM, SSC, and TA under increased growing temperature were also observed for strawberries [34] in controlled greenhouse experiments, in studies with different production environments [13] and different meteorological conditions of growing sites or growing years [17]. This observation is also in agreement with the general acceptance that too warm pre-harvest condition negatively influences the respiratory metabolism of plants and fruits. For instance, results of Wang and Camp [34] showed, that total carbohydrates in leaves, crowns and roots decreased, when day/night temperature where higher than $25 / 12^{\circ} \mathrm{C}$. According to Hellmann and Travis [11] temperatures higher than $35-40^{\circ} \mathrm{C}$ inhibit plant growth. Such maximum temperatures were achieved several times during fruit development at Gei-D.

In our study, there was no strong relationship between PAR and DM, SSC and TA (Table 8). Positive correlations were only found for DM and SSC within cv. Korona. In a recent study a positive effect of global radiation on SSC were found [13] indicating an increased photosynthetic production of sugars. In contrast, in the same study DM was negatively linked to global radiation [13] mainly because open field production was compared with protected 
Table 7

Yearly mean of the fruit quality characteristics DM, SSC, and TA for three strawberry cultivars in two years at different sites in Europe

\begin{tabular}{|c|c|c|c|c|c|c|c|}
\hline & \multicolumn{2}{|c|}{ Stj-N } & \multirow{2}{*}{$\begin{array}{c}\text { Cop-DK } \\
2009\end{array}$} & \multicolumn{2}{|c|}{ Gei-D } & \multicolumn{2}{|c|}{ Con-CH } \\
\hline & 2008 & 2009 & & 2008 & 2009 & 2008 & 2009 \\
\hline \multicolumn{8}{|l|}{ Elsanta } \\
\hline Dry matter $(\%)$ & $12.4 \mathrm{a}$ & $11.0 \mathrm{a}$ & $10.0 \mathrm{ab}$ & $8.4 \mathrm{~b}$ & $8.9 b$ & $9.3 b$ & $10.3 \mathrm{ab}$ \\
\hline Soluble solids $(\%)$ & $10.3 \mathrm{a}$ & $9.5 \mathrm{a}$ & $8.9 \mathrm{a}$ & $7.1 \mathrm{~b}$ & $6.6 b$ & $7.7 \mathrm{~b}$ & $7.5 b$ \\
\hline Total acidity $\mu \mathrm{g} / \mathrm{L}$ ) & $9.1 \mathrm{a}$ & $10.0 \mathrm{a}$ & $8.3 b$ & $7.2 \mathrm{c}$ & $7.3 \mathrm{bc}$ & $7.2 \mathrm{c}$ & $7.9 b c$ \\
\hline \multicolumn{8}{|l|}{ Korona } \\
\hline Dry matter $(\%)$ & $11.2 \mathrm{ab}$ & $11.6 \mathrm{a}$ & $9.8 \mathrm{abc}$ & $8.4 \mathrm{c}$ & $9.3 \mathrm{bc}$ & & \\
\hline Soluble solids $(\%)$ & $9.8 \mathrm{ab}$ & $10.2 \mathrm{a}$ & $8.5 b c$ & $7.4 \mathrm{c}$ & $7.1 \mathrm{~d}$ & & \\
\hline Total acidity $\mu \mathrm{g} / \mathrm{L}$ ) & $8.2 \mathrm{a}$ & $9.8 \mathrm{a}$ & $9.1 \mathrm{a}$ & $7.9 \mathrm{a}$ & $7.6 \mathrm{a}$ & & \\
\hline \multicolumn{8}{|l|}{ Clery } \\
\hline Dry matter $(\%)$ & & & & $9.5 \mathrm{a}$ & $9.7 \mathrm{a}$ & $9.6 \mathrm{a}$ & $9.8 \mathrm{a}$ \\
\hline $\operatorname{SSC}(\%)$ & & & & $7.9 \mathrm{a}$ & $8.0 \mathrm{a}$ & $7.7 \mathrm{a}$ & $7.7 \mathrm{a}$ \\
\hline Total acidity $\mu \mathrm{g} / \mathrm{L}$ ) & & & & $7.3 \mathrm{a}$ & $7.2 \mathrm{a}$ & $6.7 \mathrm{a}$ & $6.7 \mathrm{a}$ \\
\hline
\end{tabular}

Data are expressed as mean of the sampling dates $(n=6)$. Means within the same row of each cultivar followed by different letters were significantly different at $p=\leq 0.05$ (Tamhane's test).

Table 8

Correlation coefficients between strawberry fruit quality attributes and temperature and PAR during one to three weeks prior harvest date for three strawberry cultivars

\begin{tabular}{|c|c|c|c|c|}
\hline & $\begin{array}{l}\text { Daily mean } \\
\text { temperature }\end{array}$ & $\begin{array}{l}\text { Daily minimum } \\
\text { temperature }\end{array}$ & $\begin{array}{c}\text { Daily maximum } \\
\text { temperature }\end{array}$ & Daily PAR \\
\hline \multicolumn{5}{|l|}{ Inner fruit quality } \\
\hline \multicolumn{5}{|l|}{ Elsanta } \\
\hline Dry matter & $-0.753^{* * 1)}$ & $-0.589^{* 1)}$ & $-0.710^{* * 1)}$ & \\
\hline Soluble solids & $-0.777^{* * 1)}$ & & $-0.767^{* * 1)}$ & \\
\hline Titratable acidity & $-0.664^{* * 2)}$ & & $-0.687^{* * 2)}$ & \\
\hline \multicolumn{5}{|l|}{ Korona } \\
\hline Dry matter & $-0.644^{* 1)}$ & & $-0.727^{* 1)}$ & $0.787^{* * 3)}$ \\
\hline Soluble solids & $-0.698^{* * 1)}$ & & $-0.817^{* * 1)}$ & $0.899^{* * 3)}$ \\
\hline \multicolumn{5}{|l|}{ Fruit colour } \\
\hline \multicolumn{5}{|l|}{ Elsanta } \\
\hline $\mathrm{L}^{*}$ & & & & $0.762 * 1)$ \\
\hline \multicolumn{5}{|l|}{ Korona } \\
\hline $\mathrm{L}^{*}$ & & & $-0.990^{* 2)}$ & $0.974^{* 2)}$ \\
\hline Hue angle & & & $-0.979^{* 2)}$ & $0.970 * 2)$ \\
\hline \multicolumn{5}{|l|}{ Clery } \\
\hline $\mathrm{L}^{*}$ & & & $-0.720^{* 2)}$ & $0.725^{* 2)}$ \\
\hline Hue angle & $-0.868^{* * 1)}$ & & $-0.862^{* * 1)}$ & $0.821^{* * 2)}$ \\
\hline
\end{tabular}

$\left.{ }^{*} p=\leq 0.05,{ }^{* *} p=\leq 0.001 ;{ }^{1}\right)=$ one week prior harvest $\left.{ }^{2}\right)=$ two weeks prior harvest ${ }^{3}$ ) $=$ three weeks prior harvest. 
A
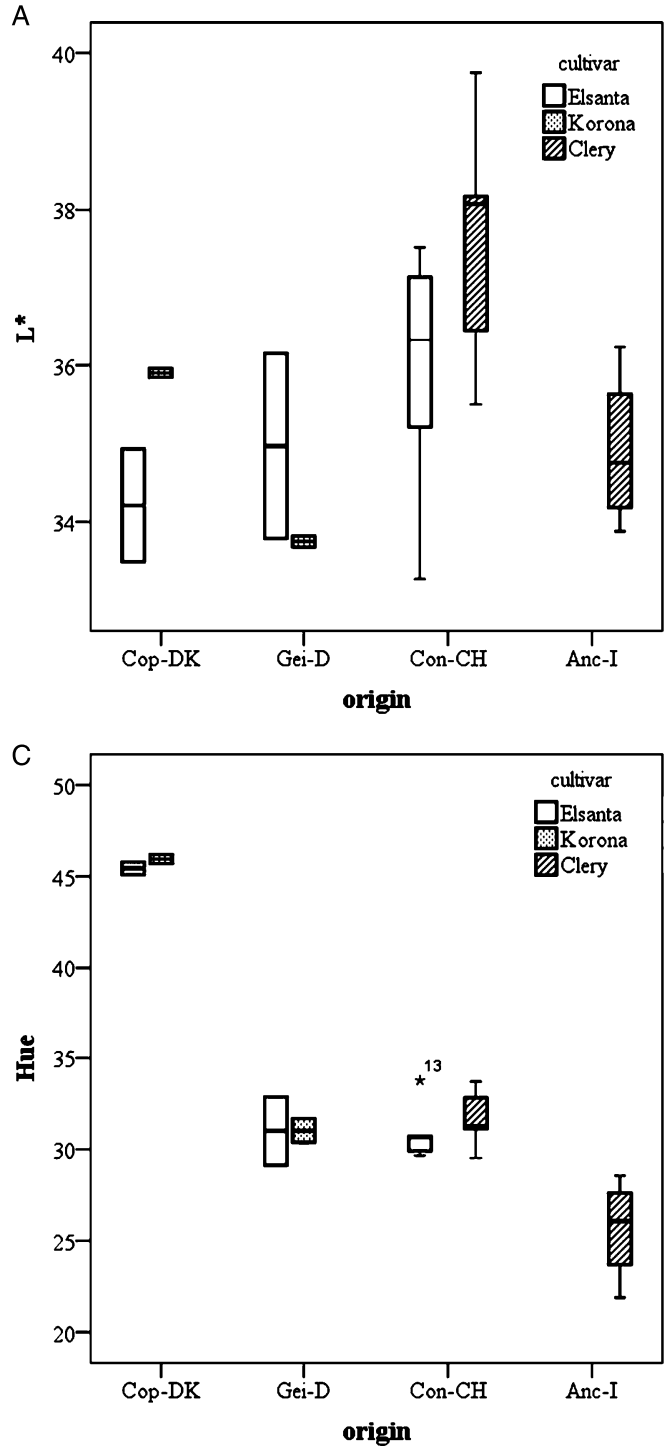

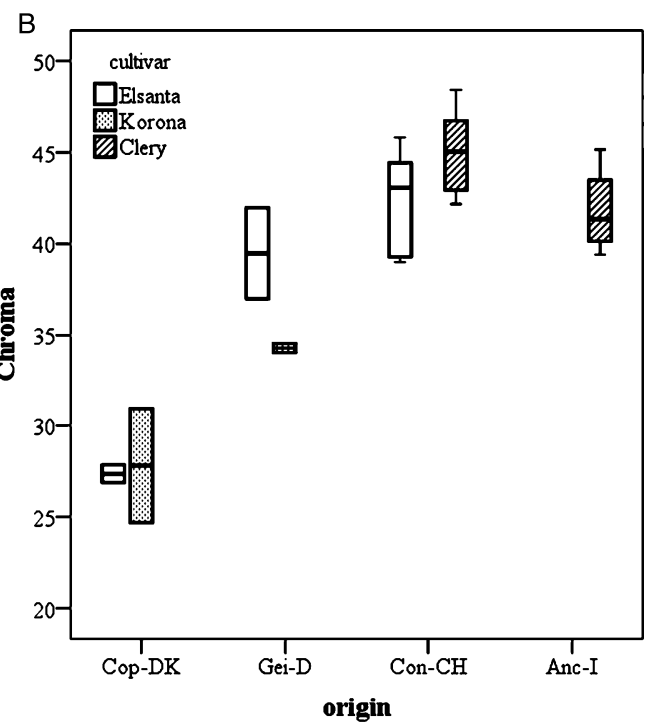

Fig. 3. Colour lightness (A), colour chroma (B) and colour hue (C) of strawberry cultivars grown at different latitudes.

cultivation under polyethylene tunnel. However, there is only scarce information available on the effect of light intensity and radiation on the mentioned quality attributes.

For cv. Clery a medium to high cultivar stability regarding DM, SSC and TA when grown at different altitudes is reported [5]. These results were supported by our own data achieved for cv. Clery, since no significant relationship was found between these quality attributes and the mentioned environmental factors (Table 8).

\subsubsection{Outer fruit quality: $L^{*}$, chroma and hue}

An increase in day/night temperatures affects fruit colour as fruit surface becomes darker (decreased $\mathrm{L}^{*}$ value), redder (reduced hue angle) and gets an intense colour saturation (increased chroma value) [13, 34].

In our study, although number of observations was limited, similar results (Fig. 3A) were obtained in tendency: at lower latitudes and thus with increasing temperature fruit of cvs. Korona and Clery became darker and fruit lightness $\mathrm{L}^{*}$ was significant negatively correlated with maximum temperature during the previous two weeks (Table 8). In 
contrast, $\mathrm{L}^{*}$ values for cv. Elsanta increased from north to south, giving fruit in the south a lighter appearance, but showed no relationship to temperature. This might reflect the fact, that in the northern countries darker fruits like those of cv. Korona are well accepted and thus cv. Elsanta fruit most likely were picked at a later ripening stage than in southern countries.

In this study, fruit of cvs. Elsanta and Korona grown at southern sites had a higher pigmentation (increased chroma values) than those grown in the north suggesting a positive temperature effect on colour saturation (Fig. 3B). However, no significant relationship was found between colour saturation and temperature.

For all cultivars fruit tint was affected by the latitude getting redder fruits (smaller hue angle) on southern sites as compared to northern ones (Fig. 3C). Hue angle (cvs. Korona and Clery) was negatively correlated to daily maximum temperature one or two weeks prior to harvest, respectively (Table 8). The redder fruit surface in this study at lower latitudes are in agreement with the findings of Josuttis et al. [16] who found in their study an increase of total anthocyanin in strawberry fruit from north to south. This increase of total anthocyanins was mainly caused by the increased content of pelargonidin 3-glucoside, which is one of the major anthocyanins giving strawberry fruit their red colour.

Lightness was also positively linked to PAR values one (cv. Elsanta) or two (cvs. Korona and Clery) weeks prior to harvest (Table 8) while hue angle of cvs. Korona and Clery was also positively correlated with PAR during the previous two weeks.

\section{Conclusion}

This evaluation was carried out with three strawberry cultivars at 5 sites covering a distance of 20 degrees of latitude in Europe. Fruit development time from anthesis to harvest start, length of harvest season, external and internal fruit quality traits were investigated with regard to temperature and PAR conditions at the different growing sites. Calculated GDD values for the phenological stage mentioned varied among the growing sites, but no relationship to latitude was found. However, calculation of GDD requires more information about base, optimum and critical upper temperatures for the different phenological stages. Results obtained on fruit quality were influenced by latitude and thus temperature giving northern sites in general the highest values of dry matter, soluble solids and titratable acidity. Fruits grown at the southern sites were redder compared to those of the north.

\section{Acknowledgments}

The experiment was initiated within the EU-COST project 863 "Euroberry" and financed by the participating institutions. The authors wish to thank all people at the different experimental sites involved in the field and analytic work for their support.

\section{References}

[1] Azodanlou R, Darbellay C, Luisier JL, Villettaz JC, Amado R. Quality assessment of strawberries (Fragaria species). Journal of Agricultural and Food Chemistry. 2003; 51: 715-21.

[2] Bigey J. Chilling requirements and compensation for the lack of chilling in strawberry. Acta Horticulturae. 2002; 567: 269-72.

[3] Black B, Frisby J, Lewers K, Takeda F, Finn C. Heat unit model for predicting bloom dates in Rubes. HortScience. 2008; 43(7): 2000-4.

[4] Carlen C, Potel AM, Ancay A. Photosynthetic Response of strawberry leaves to changing temperatures. Acta Horticulturae. 2008; 838: 73-6.

[5] Crespo P. Variability of health and taste promoting compounds in strawberry (Fragaria $\times$ ananassa Duch.) fruits. Dissertation. ETH No. $19164 ; 2010$.

[6] Døving A, Måge F. Prediction of the strawberry season in Norway. Acta Agriculturae Scandinavia, Section B, Soil and Plant Science. 2001; 51: 28-34.

[7] Døving A, Måge F. Prediction of strawberry fruit yield. Acta Agriculturae Scandinavia, Section B, Soil and Plant Science. 2001 ; 51 : 35-42. 
[8] Faedi W, Ancay A, Bartual R, Baruzzi G, Baudino M, Anna FD, Guerriero Costa JM, Lopez Aranda JM, Medina JJ, Mennone C, Mezzetti B, Navatel JC, Neuweiler R, Paroussi G, Paydas S, Ponson S, Roudeillac P. European network for strawberry cultivar evaluation: Results in southern Europe countries. Acta Horticulturae. 2004; 649: 141-5.

[9] Guttridge CG. The effects of winter chilling on the subsequent growth and development on the cultivated strawberry plant. Journal Horticultural Science. 1958; 33: 119-27.

[10] Hancock JF, The strawberry, CAB International, Oxfordshire, Great Britain; 1999, p. 95-99.

[11] Hellmann EW, Travis JD. Growth inhibition at high temperatures. Advanced Strawberry Production. 1988; 7: 36-8.

[12] Hietaranta T, Svenson B, Daugaard H. European network for strawberry cultivar evaluation: Summary results of the strawberry cultivar trials from the Nordic countries. Acta Horticulturae. 2004; 649: 131-6.

[13] Hoppula KB, Karhu ST. Strawberry fruit quality responses to the production environment. Journal Food Agriculture \& Environment. 2006; 4: $166-70$.

[14] Hortyński JA, Liniewicz K, Hulewicz T. Influence of some atmospheric factors affecting yield and single fruit weight in strawberry. Journal of Horticultural Science. 1994; 69: 89-95.

[15] Hung Y-C. Effect of curvature and surface area on colorimeter readings - a model study. Journal Food Quality. 1990; 13: 259-69.

[16] Josuttis M, Carlen C, Crespo P, Nestby R, Toldam-Andersen TB, Dietrich H, Krüger E, A comparison of bioactive compounds of strawberry fruit from Europe affected by genotype and latitude. Journal of Berry Research. 2012; 2: 73-95.

[17] Kallio H, Hakala M, Pelkkikangas A-M, Lapvetläinen A. Sugars and acids of strawberries. European Food Research Technology. 2000; 212: 81-5.

[18] Koch M, Influence of different cultivation techniques on the prediction of harvest season and yield of strawberry grown at Geisenheim; in German language. Diploma thesis, University of Applied Sciences, Wiesbaden; 2004.

[19] Krüger E, Krieg R, Innerhofer G, Latet G, Lieten F, MacNaeidhe F, Evenhuis B, Kruczynska E, Zurawicz E, Raffle S. Synthesis of the central European strawberry cultivar results. Acta Horticulturae. 2004; 649: 137-40.

[20] Kurokura T, Inaba Y, Neri D, Sugiyama N. A morphological study of the development of the second inflorescence in strawberry (Fragaria $x$ ananassa Duch.). Annales of Applied Biology. 2005; 146: 511-5.

[21] Lantin B. Récolte des cassis: Determination et prévision d'une date optimale. Bulletin petits fruits. $\mathrm{N}^{\circ} 28$. juin 1986.

[22] Le Mière P, Hadley P, Darby J, Battey NH. The effect of thermal environment, planting date and crown size on growth, development and yield of Fragaria $\times$ ananassa Duch. Journal Horticultural Science and Biotechnology. 1998; 73: 786-95.

[23] Lieten P. Koedebehoefte rechttreekse planting op substrate. Proeftuinnieuws. 1995; 22: 46-7.

[24] Lieten P. Chilling unit model for greenhouse production of strawberry cv. Elsanta. Acta Horticulturae. 2006 ; 708 : 381-7.

[25] McMaster G, Wilhelm WW. Growing degree days: One equation, two interpretations. Agricultural and Forest Meterorology. 1997; 87: 291-300.

[26] Nestby R, Winter cover affecting freezing injury in strawberries in a coastal and a continental climate. Journal Horticultural Science and Biotechnology. 2000; 75(1): 119-25.

[27] Pritts M, Luby J. Stability indices for horticultural crops. Horticultural Science. 1990; 25(7): 740-5.

[28] Sagar JC, Craig Mc Farlane J. Radiation, In: Plant growth chamber handbook, by Langhans RW, Tibbitts TW, North Central Regional Research Publication No. 340, Iowa Agriculture and Home Economics Experiment Station Special Report No. 99, Iowa State University of Science and Technology; 1997. 1-30.

[29] Sønsteby A, Karhu S. Strawberry production, growth and development in northern climate. International Journal of Fruit Science. 2005; 5(1): 107-14.

[30] Sønsteby A, Heide O. Temperature limitations for flowering in strawberry and raspberry. Acta Horticulturae. 2009 ; 838: 93-7.

[31] Tehranifar A, Le Miére P, Battey NH, The effect of lifting date, chilling duration and forcing temperature on vegetative growth and fruit production in the June-bearing strawberry cultivar Elsanta. Journal Horticultural Science and Biotechnology. 1998; 73(4): 453-60.

[32] Verheul MI, Sønsteby A, Grimstad S. Influences of day and night temperatures on flowering of Fragaria x ananassa Duch. cvs. Korona and Elsanta, at different photoperiods. Scientia Horticulturae. 2007; 112: 200-6.

[33] Wahdan HA, Waister PD, Flower initiation, fruit production and vegetative development in non-induced strawberry plant exposed to outdoor conditions in Scotland. Journal Horticultural Science. 1984; 59(2): 187-96.

[34] Wang SY, Camp MJ. Temperatures after bloom affect plant growth and fruit quality of strawberry. Scientia Horticulturae. 2000 ; 85: 183-99. 